\title{
Divisive or facilitative: The two faces of technology in CSCL
}

\author{
Carolyn P. Rosé ${ }^{1} \cdot$ Sten Ludvigsen ${ }^{2} \cdot$ Nancy Law $^{3}$. \\ Ulrike Cress $^{4} \cdot$ Gerry Stahl $^{5}$
}

(C) International Society of the Learning Sciences, Inc. 2017

\section{Introduction}

This edition of the CSCL journal includes four articles covering a diversity of methodologies and subject-matter domains. We may view technology used in the midst of collaboration as having two opposing faces, alternatively divisive or facilitating. With each passing fad, it is tempting to think of new technologies in terms of the potential for positive impact they may have. Nevertheless, in response to waves of hype that come and go, in this journal there have been strands in which even the concept of media effects itself has been challenged, and the take-home message for us is that affordances are created through design to the extent that appropriate principles have been applied in an effective way. Now we consider another side:

Carolyn P. Rosé

cprose@cs.cmu.edu

Sten Ludvigsen

Sten@ijCSCL.org

Nancy Law

Nancy@ijCSCL.org

Ulrike Cress

Ulrike@ijCSCL.org

Gerry Stahl

Gerry@ijCSCL.org

1 Carnegie Mellon University Language Technologies Institute and HCI Institute, Gates-Hillman

Center 5415, 5000 Forbes Ave, Pittsburgh, PA 15213-3891, USA

2 University of Oslo, Oslo, Norway

3 University of Hong Kong, Hong Kong, China

4 Knowledge Media Research Center, Tübingen, Germany

5 Drexel University, Philadelphia, PA, USA 
the role of the student in either taking up or transforming the affordances that were intended by the designers, potentially in ways that are contrary to the intention. In particular, the first article exposes one face of technology: investigating the extent to which social positioning around technology may be divisive in that it offers an opportunity for vying for power differentials in interaction. Here we do not blame the technology or even the design, but we explore how the students who interact around the technology may orient towards it in a dysfunctional way. The later three articles cast technology in a more typically positive light, investigating technology as scaffolding in the form of three different types of scriptbased support.

\section{Cracking her codes: Understanding shared technology resources as positioning artifacts for power and status in CSCL environments}

Simpson, Bannister, and Matthews present a qualitative analysis of two collaborative groups working together at an all female Cryptography Summer Camp for secondary school students. Students worked in pairs using computer equipment and advanced mathematical modeling tools. This in depth multi-dimensional analysis of video is meant to investigate how learning arises through active engagement between collaborating peers. Both verbal and nonverbal cues were used in the analysis. Artifacts play a prominent role in the analysis. This study builds on a history of investigation into collaboration around touch technologies such as mobile devices (White 2006) and tabletops (Tissenbaum et al. 2017) as well as work on computer-supported science inquiry (Arnseth and Krange 2016).

From a theoretical standpoint, positioning theory (Davies and Harré 1990) is used in this work specifically as a lens for studying power relationships and authority over knowledge and how these are negotiated during collaboration. In positioning theory, the rhetorical choices made by speakers are used to negotiate with one another for a place within a conceptual space relative to one another. Metaphorically speaking, the participants in an interaction may be placed in proximity to one another on a variety of dimensions including emotional closeness, power, and status. Unlike in the concept of roles, which are more static, positioning can change from time to time throughout an extended interaction. These shifts are consequential for interaction analysis. They render status differences as achievements in interaction rather than as a given. Connections between the positioning of group members around technology and the power relations between group members are explored in this article. The connection between status differences and productivity during collaboration is also explored.

The qualitative approach is motivated by prior work illustrating the important mediating effects of factors such as problem type, group size, role assignment, self-efficacy, etc. These findings raise important questions about how group processes are influenced by these factors. What is the mechanism through which these factors influence group outcomes? A qualitative approach enables taking an in-depth look at these processes, though of a small number of groups. An important point is that subtle effects of social positioning on interaction and ultimately learning may go undetected when data is viewed in terms of statistical distributions.

The article is rich with blow-by-blow descriptions and illustrative excerpts. Two specific case studies are examined as positioning is negotiated over time. The dyads in the two studies are examined both individually and in comparison to one another. The article raises questions about potential ill effects of power differentials and how these might be mitigated. 


\section{Facilitating socio-cognitive and socio-emotional monitoring in collaborative learning with a regulation macro script: An exploratory study}

The first article in this issue explored potential problems in collaboration, which paves the way for the three following articles, each of which explores a different scripting intervention intended to overcome such problems. The first such article, authored by Näykki, Isohätälä, Järvelä, Pöysä-Tarhonen \& Häkkinen, presents an exploratory study of regulation in groups of teacher-education students whose collaborative learning was supported by a script designed to support regulation during a six week environmental-science course. In contrast to the two later articles, which focus on Micro scripts, this study investigates Macro scripts, which support collaboration at a coarse-grained level through orchestration of activities and processes (Dillenbourg and Hong 2008; Tchounikine 2016; Dillenbourg and Tchounikine 2007).

What are investigated in particular are socio-cognitive and socio-emotional monitoring processes during more or less active discussions in which the Macro script is used to structure the activity in productive ways. This refers to considering and evaluating the understanding, reasoning, and progress of self and other in interactions. Building on Järvelä et al. (2016a, b), this article fills an important gap in the literature regarding the ways in which script-based support can be used to scaffold regulation. In particular, Näykki and colleagues argue that there is a dearth of studies exploring how to support strategies related to planning, monitoring and evaluating group processes through script-based support. The goal of the intervention in this study is to increase awareness of the learning processes of self and other so that they can be improved. A strong point of the article is that it specifically investigates script appropriation, enabling readers to see how the scripted activities that participants engage in are enacted, and even more importantly, what happens during unscripted collaborative learning that follows the scripted phase.

The video data collected in this study is segmented and coded so that analyses of temporal patterns can be conducted. The methodology integrates both quantitative and qualitative elements. Though the data is reduced through a rigorous coding process applied to $30-\mathrm{s}$ segments of video using a reliable coding scheme, rich qualitative observations of the data are made available as well. The coding enables visual time-series maps of monitoring behaviors to be constructed and analyzed. Qualitative observation facilitates insightful interpretation of patterns found. Results differed by phase of the activity. Relationships between social and cognitive variables are investigated.

\section{How to combine collaboration scripts and heuristic worked examples to foster mathematical argumentation: When working memory matters}

Adding to the diversity of domains represented in this issue's papers, the third paper focuses on post-secondary mathematics, specifically within a two-week preparatory course for prospective mathematics university students. Within the general area of Mathematical Argumentation Skills (MAS), this paper focuses on acquisition of the skill of argumentation itself and how this learning is impacted by scaffolding. It builds on a number of very important and influential studies on collaboration scripts by Fischer and colleagues (Fischer et al. 2013) as well as others in the broader community (Schellens et al. 2007; Rummel et al. 2012). This paper in particular addresses important questions related to the integration of scripts with heuristic worked examples, which prior work suggests can both provide effective scaffolding for MAS 
(Kollar et al. 2014). A challenge in integration of multiple forms of scaffolding is the danger of over-scripting or script interference. A novel aspect of this work is its investigation of fading of scripts, which is a topic that has been of interest for over a decade, with few landmark studies so far (Wecker and Fischer 2011). This issue is still associated with many open and difficult questions, but offers promise for reducing scripting over time and thus potentially avoiding over-scripting. Two notions of MAS inform this work: namely, dialogic and dialectic (Schwarz and Shahar 2017; Wegerif 2008).

The paper follows a hypothesis-testing paradigm where a factorial design is employed to tease apart the separate and joint effects of the two manipulations of interest, namely fading or not and ordering of types of scaffolding. A rigorous statistical analysis is presented. The design of the large, empirical investigation involving 108 students shows sensitivity to two important student-level variables, namely prior knowledge and working-memory capacity.

The paper explores an interesting connection between these factors in the Matthew Effect, where low prior knowledge may increase the cognitive load associated with utilizing scaffolding even though its purpose is to assist those with low prior knowledge. In that case, the scaffolding may in fact end up having more impact on high-prior-knowledge students instead. The Matthew Effect provides a valuable lens for making sense out of the pattern of results. The study ends with a wealth of ideas for future work refining the concept of fading of scaffolding, as well as additional research questions. In connection with the theme of this editorial introduction, the authors point out that interesting follow-up research would investigate the concept of fading in connection with the different ways in which individual students appropriate the scripts (Tchounikine 2016). Delving into questions about methods for fading in connection with differences in appropriation trajectories for students raises questions about the potential for dynamic fading that might respond to differences in argumentation patterns as they occur in real time based on automated analysis (Adamson et al. 2014; Rosé et al. 2008).

\section{Investigating the effects of peer-to-peer prompts on collaborative argumentation, consensus and perceived efficacy in collaborative learning}

In the final paper in this issue, Harney and Hogan continue the theme of argumentation as a mode of collaborative discourse in their experimental study embedded in an undergraduate Psychology course. Their work builds on earlier findings related to positive effects of processlevel prompts in collaborative-learning contexts (Harney et al. 2015) and a long and intensive interest in argumentation within the Computer-Supported Collaborative Learning community (Scheuer et al. 2010). It is motivated not just by the goal of student learning or even lifelong learning, but by the important role of collaboration, and thus of collaborative skills, in the workplace and in modern life generally. The interesting contrast explored in this paper involves the locus of the scaffolding. What is unique about this paper within this issue is its focus on peer learning, by which the authors mean focusing on prompting, feedback, and assessment amongst peers. In one condition of the study, scaffolding prompts are delivered by an instructor. In another condition, an instructor first models the prompts, but then students take on the responsibility for prompting each other. The authors tie their focus on peer learning to the vision of lifelong learning, with the idea that in peer learning students gain skills that enable them to make better use of their social connections as learning resources. Furthermore, as students learn to use their peer connections as learning resources, they also have more resources in their university context, where instructor time is limited. 
One concern with peer feedback is the variable quality, so an extensive review of literature on factors leading to poor or high quality peer feedback are reviewed. Poor quality peer feedback has been the target problem in much recent research regarding learning at scale. In this work, a micro-script is used to offer instructional support for the peer feedback. A number of summative outcomes are explored in this study, including perceived consensus, perceived efficacy, discomfort within the group, and team orientation. But in addition to this, in the same spirit as the Näykki et al. paper, a process analysis is produced through rigorous application of a coding scheme, this time using the Conversational Argument Coding Scheme (Seibold and Meyers 2007) to explore argumentation style and complexity. Statistical connections between process and outcome variables are also explored.

The results of the study suggest exciting new roles for peer learning in classrooms. Future work will be needed to follow up on the promising results of this study. Questions related to gender and culture effects are also raised and left for future work.

\section{Conclusion}

Across the four papers of this issue, we have explored collaboration across multiple domains and levels of education through multiple different theoretical and methodological lenses. The series of papers presented in this issue begins with one focusing on potential difficulties in small group dynamics and ends with one arguing for the tremendous societal importance of collaborative learning in general and the fostering of collaborative skills in particular. Ultimately, one important thrust of work in the field of CSCL is using technology to host productive engagement between people for the purpose of learning and growth. The long and productive trackrecord of this community for producing new knowledge towards shaping collaborative encounters in a positive way through technology design supports this view. As the field moves forward towards bigger and bigger societal challenges, including important concerns regarding equity highlighted at the most recent CSCL conference, we will continue to challenge our past successes and strive for more robust solutions that stand up in the face of the difficulties.

\section{References}

Adamson, D., Dyke, G., Jang, H. J., \& Rosé, C. P. (2014). Towards an agile approach to adapting dynamic collaboration support to student needs. International Journal of AI in Education, 24(1), 91-121.

Arnseth, H. C., \& Krange, I. (2016). What happens when you push the button? Analyzing the functional dynamics of concept development in computer supported science inquiry. International Journal of Computer-Supported Collaborative Learning, 11, 479-502. https://doi.org/10.1007/s11412-016-9244-4.

Davies, B., \& Harré, R. (1990). Positioning: The discursive production of selves. Journal for the Theory of Social Behaviour, 20(1), 43-63.

Dillenbourg, P., \& Hong, F. (2008). The mechanics of CSCL macro scripts. International Journal of ComputerSupported Collaborative Learning, 3(1), 5-23. https://doi.org/10.1007/s11412-007-9033-1.

Dillenbourg, P., \& Tchounikine, P. (2007). Flexibility in macro-scripts for computer-supported collaborative learning. Journal of Computer Assisted Learning, 23(1), 1-13. https://doi.org/10.1111/j.13652729.2007.00191.x.

Fischer, F., Kollar, I., Stegmann, K., \& Wecker, C. (2013). Toward a script theory of guidance in computersupported collaborative learning. Educational Psychologist, 48(1), 56-66. https://doi.org/10.1080 $/ 00461520.2012 .748005$.

Harney, O. M., Hogan, M. J., Broome, B., Hall, T., \& Ryan, C. (2015). Investigating the effects of prompts on argumentation style, consensus and perceived efficacy in collaborative learning. International Journal of Computer-Supported Collaborative Learning, 10(4), 367-394. 
Järvelä, S., Kirschner, P. A., Hadwin, A., Järvenoja, H., Malmberg, J., Miller, M., \& Laru, J. (2016a). Socially shared regulation of learning in CSCL: Understanding and prompting individual- and group-level shared regulatory activities. International Journal of Computer-Supported Collaborative Learning, 11(3), 263-280. https://doi.org/10.1007/s11412-016-9238-2.

Järvelä, S., Järvenoja, H., Malmberg, J., Isohätälä, J., \& Sobocinski, M. (2016b). How do types of interaction and phases of self-regulated learning set a stage for collaborative engagement? Learning and Instruction, 43, 3951. https://doi.org/10.1016/j.cedpsych.2017.01.009.

Kollar, I., Ufer, S., Reichersdorfer, E., Vogel, F., Fischer, F., \& Reiss, K. (2014). Effects of collaboration scripts and heuristic worked examples on the acquisition of mathematical argumentation skills of teacher students with different levels of prior achievement. Learning and Instruction, 32(1), 22-36. https://doi.org/10.1016/j. learninstruc.2014.01.003.

Rosé, C. P., Wang, Y. C., Cui, Y., Arguello, J., Stegmann, K., Weinberger, A., \& Fischer, F. (2008). Analyzing collaborative learning processes automatically: Exploiting the advances of computational linguistics in computer-supported collaborative learning. International Journal of Computer Supported Collaborative Learning, 3(3), 237-271.

Rummel, N., Mullins, D., \& Spada, H. (2012). Scripted collaborative learning with the cognitive tutor algebra. International Journal of Computer-Supported Collaborative Learning, 7(2), 307-339. https://doi. org/10.1007/s11412-012-9146-z.

Schellens, T., Van Keer, H., De Wever, B., \& Valcke, M. (2007). Scripting by assigning roles: Does it improve knowledge construction in asynchronous discussion groups? International Journal of Computer-Supported Collaborative Learning, 2(2-3), 225-246. https://doi.org/10.1007/s11412-007-9016-2.

Scheuer, O., Loll, F., Pinkwart, N., \& McLaren, B. M. (2010). Computer-supported argumentation: A review of the state of the art. International Journal of Computer-Supported Collaborative Learning, 5(1), 43-102. 1392. https://doi.org/10.1007/s11412-009-9080-x.

Schwarz, B. B., \& Shahar, N. (2017). Combining the dialogic and the dialectic: Putting argumentation into practice for classroom talk. Learning, Culture and Social Interaction, 12, 113-132. https://doi.org/10.1016/j. lcsi.2016.12.003.

Seibold, D. R., \& Meyers, R. A. (2007). Group argument: A structuration perspective and research program. Small Group Research, 38(3), 312-336. 1388. https://doi.org/10.1177/1046496407301966.

Tchounikine, P. (2016). Contribution to a theory of CSCL scripts: Taking into account the appropriation of scripts by learners. International Journal of Computer-Supported Collaborative Learning, 11(3), 349-369.

Tissenbaum, M., Berland, M., \& Lyons, L. (2017). DCLM framework: Understanding collaboration in openended tabletop learning environments. International Journal of Computer-Supported Collaborative Learning, 12, 35-64. https://doi.org/10.1007/s11412-017-9249-7.

Wecker, C., \& Fischer, F. (2011). From guided to self-regulated performance of domain-general skills: The role of peer monitoring during the fading of instructional scripts. Learning and Instruction, 21(6), 746-756. https://doi.org/10.1016/j.learninstruc.2011.05.001.

Wegerif, R. (2008). Dialogic or dialectic? The significance of ontological assumptions in research on educational dialogue. British Educational Research Journal, 34(3), 347-361. https://doi.org/10.1080/01411920701532228.

White, T. (2006). Code talk: Student discourse and participation with networked handhelds. International Journal of Computer-Supported Collaborative Learning, 1(3), 359-382. 